\title{
TOWARDS MULTI-OBJECTIVE DESIGN OF EV-55 WINGLET WITH INTEGRATED VHF ANTENNA
}

\section{EMUS 2019}

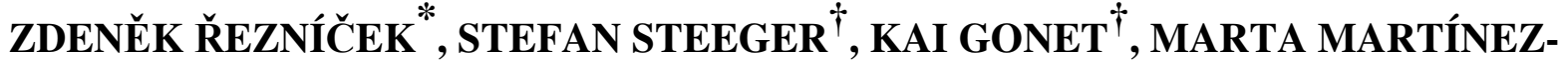 \\ VÁZQUEZ ${ }^{\dagger \dagger}$, JORDI BALCELLS-VENTURA ${ }^{\dagger \dagger}$, PETER VRCHOTA ${ }^{\dagger \dagger}$, \\ VICTOR LUNGAHO ${ }^{\dagger \dagger \dagger \dagger}$ \\ ${ }^{*}$ Evektor, spol. s r.o. \\ Letecká 1008, Kunovice, Czech Republic \\ e-mail: engineering@evektor.cz,www.evektor.cz \\ ${ }^{\dagger}$ INVENT GmbH \\ Christian-Pommer-Straße 34, 38112 Braunschweig \\ email: info@invent-gmbh.de, www.invent-gmbh.de \\ †' IMST GmbH \\ Carl-Friedrich- Gauß-Str. 2-4, 40223 Kamp-Lintfort, Germany \\ email: contact@imst.com,www.imst.com \\ ${ }^{\dagger \dagger}$ Czech Aerospace Research Centre (VZLU) \\ Beranovych 130, 19905 Prague, Czech Republic \\ e-mail: vrchota@vzlu.cz, web page: http://www.vzlu.cz \\ ††† Trackwise Designs plc \\ 1 Ashvale Alexandra Way, Ashchurch, Tewkesbury, Gloucestershire, England \\ email: victor.lungaho@trackwise.co.uk, www.trackwise.co.uk
}

Key words: VHF antenna, electromagnetics, aerodynamics, stress analysis, winglet, aircraft

Abstract. The article is devoted to highlight the challenges, bottlenecks and possible solutions of VHF antenna integrated into a winglet from both the designer's and the airframer's perspective. We look into pros and cons specific for different antenna solutions and discuss ways how to protect them against possible electromagnetic environmental effects. As an outlook, a winglet with integrated VHF notch antenna designed within the ACASIAS project will be described in better detail.

\section{INTRODUCTION}

Modern winglet designs tend to introduce more functions than simply improving the efficiency of fixed-wing aircraft by reducing drag. As an example, integration of position and anti-collision lights represents one of the most common ways how to effectively utilize the winglet in more than one way. Hand in hand with new manufacturing technologies and materials, there is an increasing tendency to integrate different types of antennas into the winglet too. This is also the case for the ACASIAS project [1], where one of the systems to be 
developed is a VHF antenna integrated into the winglet.

A successful design of winglets with integrated antennas is relatively complex and multidisciplinary task, especially when taking into consideration all possible technical tradeoffs and bottlenecks [2], [3]. Biggest portion of possible difficulties usually falls into the following three fields of the design: aerodynamics, stress analysis and electromagnetics. However, the design of all such systems integrated in the winglet should be carried out in continuance of development of an aircraft, taking into consideration all system safety analyses at its beginning up to the certifiability, maintainability and repairability at the final stages.

The most basic problem is already to attach a winglet to a pre-existing wing of an aircraft to increase its performance and efficiency. When installing a new winglet to an aircraft, it is necessary to take into account possible additional reengineering and recertification works on a wing, which can be restrictive from time and economical perspective. This is why aftermarket installations are mostly viable only for large airplanes. The first main reason is possibility of adding originally unforeseen stress to a wing structure. The critical factor here is the influence of a winglet on load distribution along the wing, especially on bending moment distribution. In general, a winglet shifts resultant air force towards the tip of a wing and consequently increases its bending moment. The second is the above-mentioned change in aerodynamic performance of an aircraft, dictated by the final shape of a winglet and critical flight scenarios (i.e. load cases) specified for an aircraft. Both, levels of final loads introduced from the winglet to the wing structure and shape of the winglet, improving final aerodynamic performance of an aircraft, represents two contradicting design goals to be solved.

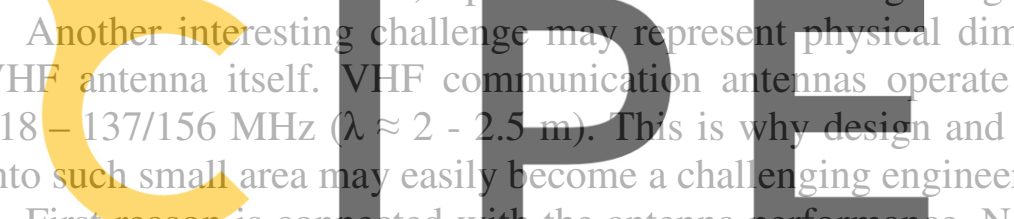

First reason is connected with the antenna per
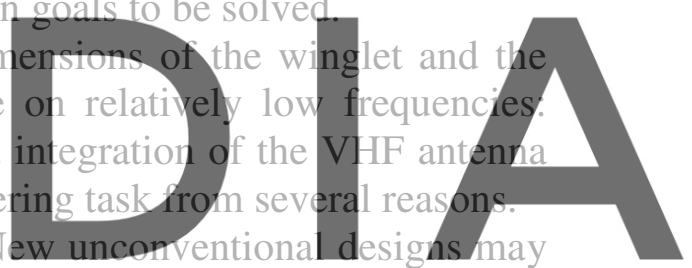

provide us with more spatially effective solutions without sacrificing necessary performance

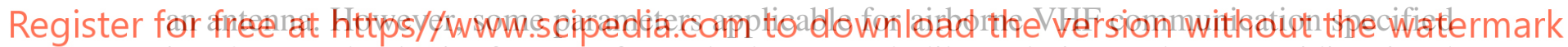
in [4] are clearly in favour of standard monopole-like solutions where omnidirectional radiation pattern of an antenna is preferred in horizontal plane. Such a requirement is not feasible for any antenna situated at the tip of a wing due to obstruction caused by an airplane.

Logical solution to get omnidirectional-like pattern for a VHF comm. system is to place two separate antennas on both ends of a wing. The solution is technically valid because it rotates (rolls) the concept defined in [4] only by $90^{\circ}$ about the longitudinal axis of an aircraft. In addition, such a solution can be combined with the standard one to obtain better coverage.

However, such a choice for the antenna position also has its clear disadvantages. Winglet parts, as structural extremities, tend to attract a lightning and hold the lightning channel (at its trailing edge) and there is a high possibility that both winglets will become a part of the lightning channel at the same time. Therefore, winglet antenna will experience more severe and hazardous environment (zones $1 \mathrm{~A}$ and $1 \mathrm{~B}$ ) and it is necessary to designed it in a way to overcome similar events without significant damage or damage to other systems behind it. This is why safe flight and landing without VHF COM antenna destroyed due to lightning has to be taken into account during aircraft safety analysis.

The last but equally important design challenges lies in the field of repairability and maintainability of the winglet antenna. Higher possibility of its damage due to a lightning 
strike, as the negative aspect of its position on an aircraft, can be compensated by winglet design to allow possible repairs of the antenna element or the structure itself. Such measures will positively influence operational and maintenance costs of the whole system.

\section{AERODYNAMIC DESIGN}

Aerodynamic design of a new winglet has been done by means of the optimization method and numerical simulations. The cost function of the optimization was minimization of the induced drag. The flow conditions corresponded to the cruise regime of the EV55 aircraft. The RANS equations were solved in in-house CFD program. All simulations were run as a fully turbulent flow using k- $\omega$ EARSM turbulence model.

The optimization strategy is based on the Design of Experiment (DoE) in connection with Response Surface Method (RSM) to find out the optimal winglet's shape from the requirements point of views. Winglet itself was parameterized by elliptic curves. Six parameters in total were used for creation of the DoE matrix. The height, dihedral, twist and its combination defined the final winglet's shape. The number of parameters with the circumscribe type of DoE defined the total number of created and calculated geometries.

Several constrains have been introduced at the beginning of the optimization. The main constrains were the maximal increment of the bending moment due to the winglet and maximal loads of the end rib of the original wing. The another constrain was the size of the winglet itself. Larger winglet is better from the VHF antenna integration point of view. The winglet size was linited by the original on one side and by the large wetred surface
(penalizing the friction drag) dn the other side.
The calculated cases from DoE after some optimization loops resulted in the final shape of
the winglet, which fulfil all requirements and constrains. The comparison of the original and
optimized shape of the winglet is depicted in Fig. 1 . More detail deseription can be found in
[3]. The performance of the optimized winglet was compared with the baseline Ev 55 aircraft with winglet and with the EV55 with original winglet. It has been found that the new winglet

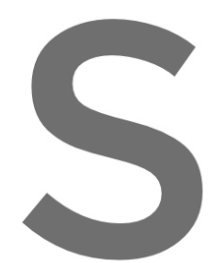

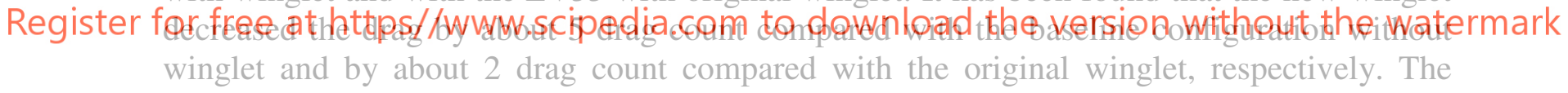
relatively small drag decrement is probably caused by the slot between the optimized winglet and aileron. This slot was not present in original winglet and has been modelled due to the horn aerodynamic balance of the aileron.

The additional critical cases were defined after the optimization to obtain the loading of the wing and winglet. The bending moment of the wing with new winglet together with the pressure distribution on the winglet's surface were calculated and exported for subsequent verification of wing's structure and structural design of the winglet itself.

1)
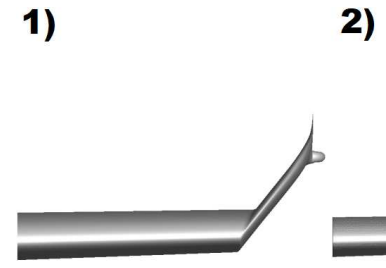

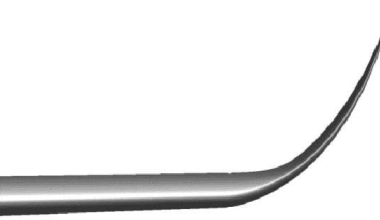

3)

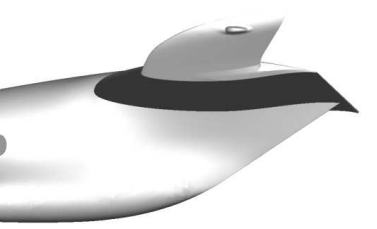

4)

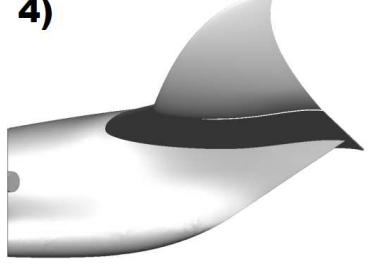

Figure 1: Comparison of the original $(1,3)$ and optimized $(2,4)$ shape of the winglet 


\section{STRUCTURAL DESIGN}

Stress distribution, derived from pressure distribution obtained from CFD analyses, and resulting loads transferred from the winglet into the EV-55 wing have been taken into account during design and optimization of the winglet structure.

The critical load case was considered for an AoA (Angle of attack) of $17^{\circ}$. The ultimate loads as a safety factor for filing parts were determined as followed: 2.25 for composite parts and 1.5 for metallic components (CS 23.303). The pressure distribution was also multiplied by this safety factor, as was the acceleration due to gravity, and was projected onto the wetted winglet surface.

The first structural model was based on a CRFP material thickness of $2.5 \mathrm{~mm}$, which corresponds to a plybook of 10 layers for the outer skin, and the first estimation of material and thicknesses provided a total weight of $11,5 \mathrm{~kg}$. This resulted in first loop of the model refinement. For the calculation, an Inverse Reserve Factor (IRF) with Tsai-Wu failure Criteria was used. The first iterations showed that the winglet is far too strong than required. This led to weight optimization. In several successive steps, the influence of the reduction in material thickness and density under the specified load was determined.

The final design is a two-shell structure with a lightweight foam core. The material thickness of the outer skin was reduced from $2.5 \mathrm{~mm}$ to $1.7 \mathrm{~mm}$ (corresponding to 7 layers). Only in the area of the winglet root is applied with $2 \mathrm{~mm}$ CFRP. The final weight is around $8,5 \mathrm{~kg}$. GFRP window enabling antenna to radiate has only little influence on the strength of the winglet.
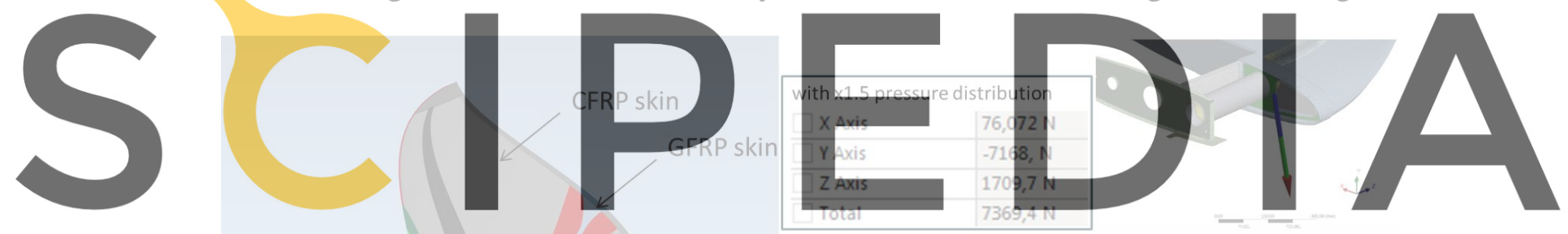

Register for free at https//www.scipedia.com ta
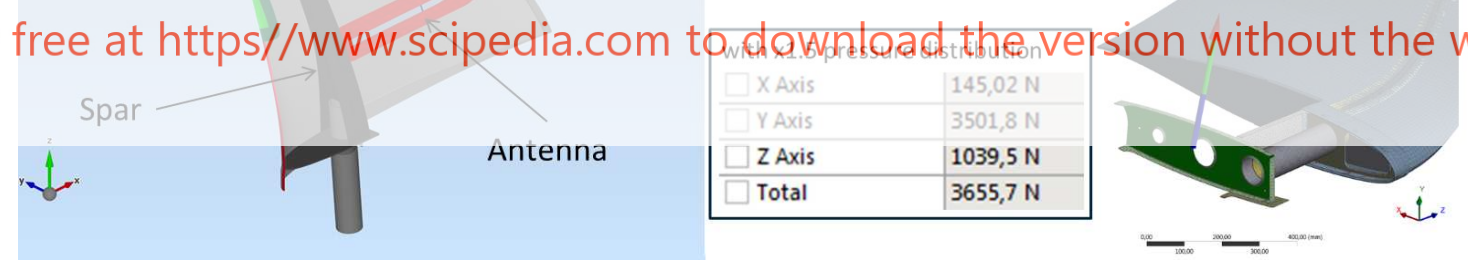

Figure 2: Main parts of the winglet, outer and inner layers (Rohacell and $\mathrm{Cu}$ mesh not shown for the sake of clarity), and support reactions transferred from the winglet into the last wing rib (green part)

The support reactions transferred from the winglet into the wing are shown in Fig. 2 (safety factor is 1.5). Assessment of the local effect of the winglet to the wing showed necessity of local structural modifications of the end part of the wing to transfer properly a local load generated by the winglet. In the further investigations, an iteration loop is once again run through in the event of bird strike. In first calculations the impulse of a bird strike on the outer tip of the winglet was applied. The deformation must not be so large that the trailing edge of the winglet may block the aileron connected to the wing. This calculation resulted in the displacement of the trailing edge by $4 \mathrm{~mm}$ in the direction of the aileron. Since the gap dimension at this position is considerably larger, this position is also to be regarded as uncritical. 


\section{ANTENNA DESIGN}

The preliminary design was performed for the basic VHF frequency band, $118-137 \mathrm{MHz}$. The antenna is integrated in the 3D volume of the winglet, taking into account the presence of other elements (e.g., lightning diverters and lights.) The winglet shell is made out of Carbon Fibre Reinforced Plastic (CFRP) covered with a copper mesh for lightning protection. A Glass Fibre Reinforced Plastic (GFRP) "window" is included to allow the antenna to radiate. The antenna itself is printed on flexible PCB (Printed Circuit Board) and placed between the CFRP/GFRP skins. The winglet is filled with foam material (Rohacell) for mechanical stability.

Different antenna concepts, namely a meandered monopole or a meandered slot (see Figure 3,) were considered for the project. To simplify the initial conceptual simulations, a planar projection of the winglet was considered, and metallic strips were added to account for the effect of the lightning diverters. Both concepts were discarded, as the required additional lightning protections on the winglet strongly degraded their performance.
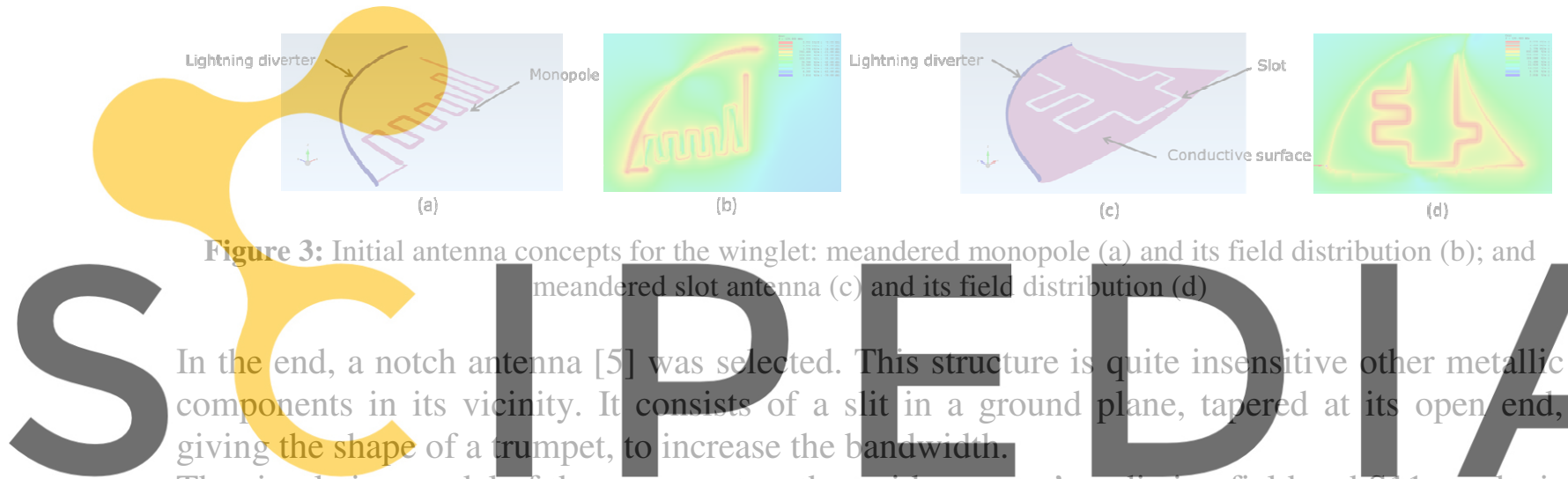

Figure 3: Initial antenna concepts for the winglet: meandered monopole (a) and its field distribution (b); and In the end, a notch antenna [5] was selected. This structure is quite insensitive other metallic
components in its vicinity. It consists of a slit in a ground plane, tapercd at its open/ end,
giving the shape of a trumpet, to increase the bandwidth.
The simulation model of the antenna, together with antenna's radiation field and S1 1 results is presented in Fig 5. The geometry, is adapted to the shape and size of the winglet, and takes

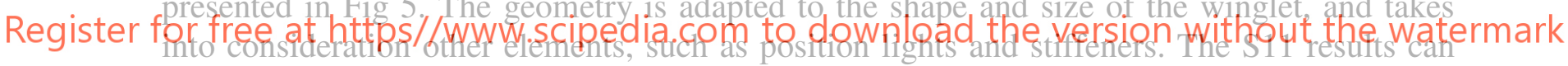
be compared with initial measurements of the antenna on a flat mockup reported in [2].
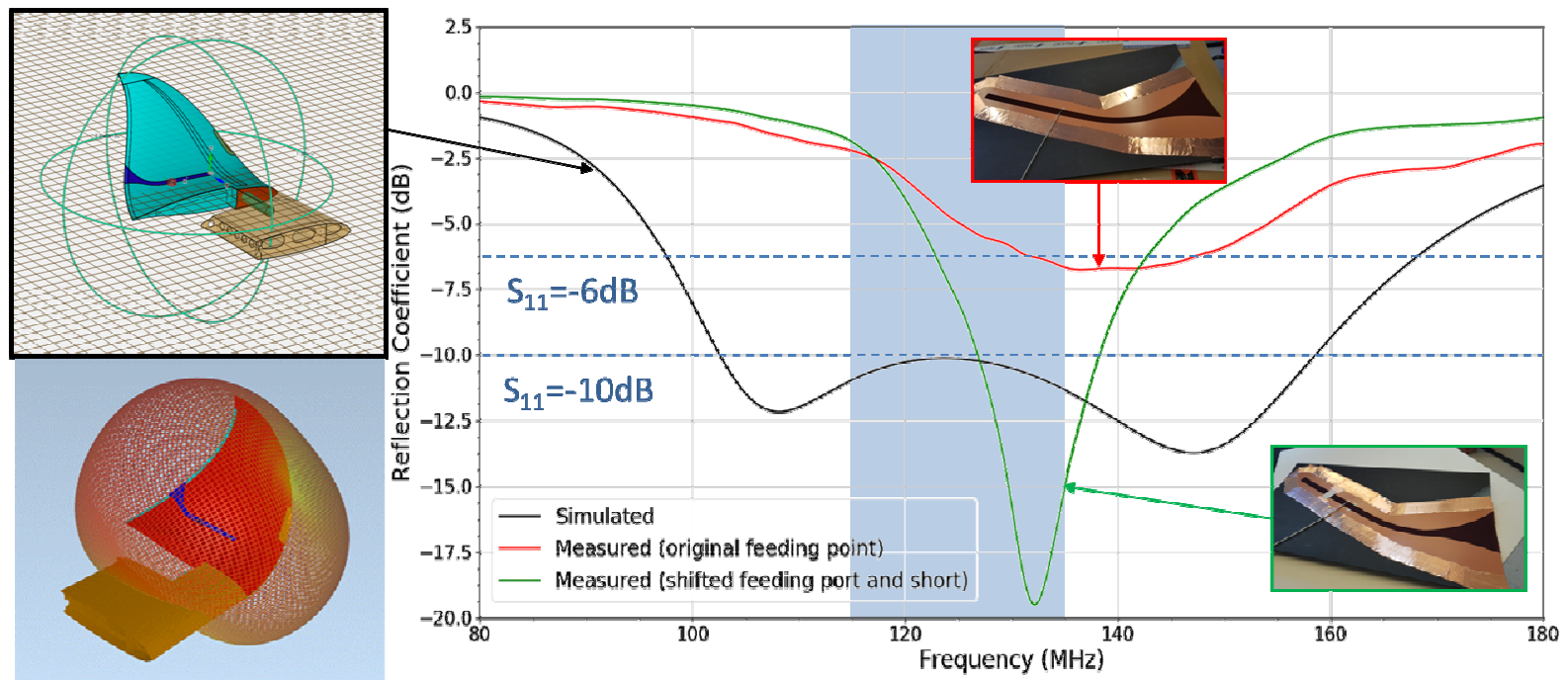

Figure 4: Simulation model representation, antenna far field and S11 results (simulation vs. mockup) 
The notch antenna (mockup) was printed on a flexible PCB and fixed on conformal-shaped shell using adhesive copper tape. The feed consists of a semi-rigid cable with a SMA connector. When using the original feeding point (determined by simulation), the antenna does not comply with the bandwidth requirements, as the conformal shell, which acts as a ground plane, is smaller than the real winglet assumed in the simulation. This causes a shift of the resonance frequency and impedance matching. The antenna can easily be tuned to meet the requirements by slightly tuning the size of the notch and shifting the feeding point.

Future work will look at integrating a flexible circuit with the notch antenna in the right position as determined by the preliminary results. This should increase reliability and perfomance by eliminating the need for a joining mechanism between the feed line and the antenna.

\section{SUMMARY}

The complexity and multidisciplinary nature of the winglet with integrated VHF antenna has been discussed from several engineering perspectives. Finding optimal design solutions for both the winglet and the antenna without using modern simulation tools would significantly prolong the time and efforts necessary to reach the final design. This applies in general to all multifunctional structures offering us new possibilities in both avionic and automotive sector.

As the introductory discussion showed, the proposed design represents only first steps on the road towards the final (commercial) product. Other design aspects like neparability, maintainability, or potential detail.

ACKNOWLEDGEMENT
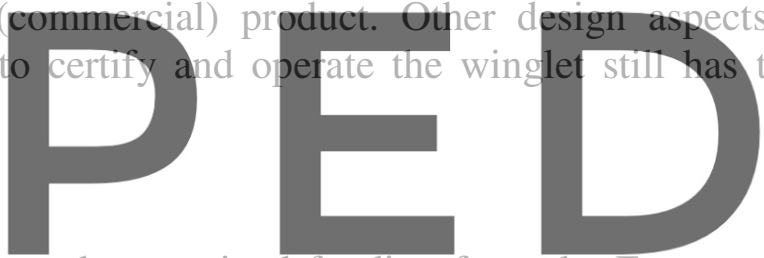

All work described in this paper has received funding from the European Union's Horizon $202 \varrho$ research and, innovation programme under grant agreement No 723167 , ACASIAS
Register for free at https//WWW.Scipedia.com to download the version without the watermark
project.

\section{REFERENCES}

[1] "Advanced Concepts for Aero-Structures with Integrated Antennas and Sensors", http://www.acasias-project.eu/

[2] M. Martínez-Vázquez, J. Balcells-Ventura, Z. Řezníček, K. Gonet, S. Steeger, P. Vrchota, V. Lungaho, „VHF notch antenna integrated in an aircraft winglet”, submitted to IEEE Antennas \& Propagation Society Symposium, Atlanta, US, 2019.

[3] P. Vrchota, S. Steeger, M. Martínez-Vázquez, M. Světlík, Z. Řezníček, “Aerodynamic and structural design of winglet with integrated VHF antenna", 8th EASN-CEAS Int. Workshop on Manufacturing for Growth \& Innovation, 2018, Available: https://doi.org/10.1051/matecconf/201823300018

[4] RTCA DO-186B, Minimum Operational Performance Standards (MOPS) for Airborne Radio Communications Equipment Operating Within the Radio Frequency range $117.975-137.000 \mathrm{MHz}$

[5] R.A. Burberry, "VHF and UHF antennas", IEE Electromagnetic series 36, Peter Peregrinus, 1992. 